\title{
A reliable tool for the improvement of micro powder injection moulds made of steel**
}

\author{
By Andreas Kienzler*, Brando Okolo, Volker Schulze, Alexander Wanner, Detlef \\ Löhe
}

\section{Introduction}

Micro powder injection moulding ( $\mu \mathrm{PIM})[1]$ is a common technique for an economic largescale production of micro parts. This process requires moulds with superior surfaces, in particular low surface roughness and beneficial residual stress states. To ensure a long service life a high wear resistance is required which can better be fulfilled by moulds made of steel than by those made of brass [2].

Today three different processes for the production of micro moulds made of steel are used: micro milling [3], electro discharge machining (EDM) [4] and laser ablation [5]. The surface quality of the moulds achieved via these processes is often inadequate for $\mu$ PIM: Micro milling generates burrs and grooves [6] whereas electro discharge machining and laser ablation create brittle and rough surface layers [7-8]. These circumstances make it necessary to develop new methods for deburring and surface quality improvement, e.g. roughness reduction or surface layer removal, which are applicable in the micro regime. In the collaborative research centre SFB 499 [9] "Development, production and quality assurance of moulded micro-components made of metallic and ceramic materials" abrasive micro peening processes [10] were chosen for smooth finishing of micro moulds because they do not require forming tools and because of their flexibility.

Abrasive micro peening based on air pressure allows reliable deburring within several minutes without creating shape errors or significant edge rounding. During abrasive micro peening, features related to the production process vanish and the final outcome is an isotropic surface topography which exhibits a reduced roughness and a beneficial residual stress state. 
In this study the focus will be on the development of specific residual stress states at and below the surface of a mechanically processed Toolox 44 sample. To this end, X-ray diffraction studies with high spatial resolution were carried out at the synchrotron radiation facility HASYLAB and at the Institute for Materials Science and Engineering $I$ at the University of Karlsruhe (TH). The results show that high compressive residual stresses are induced by the micro peening process in the near-surface layers of the micro moulds. These residual stresses are evenly distributed over the peened surface area, this being indicative of the high uniformity of the peening process. It is expected that these high and evenly distributed compressive residual stresses enhance the fatigue properties and thus the service lifetime of the moulds.

\section{Experimental}

The material used in this study is a commercial Toolox 44 steel type which had been quenched and tempered. Cavities of similar shapes (size: $6 \mathrm{~mm} \times 6 \mathrm{~mm}$, depth $50 \mu \mathrm{m}$ ) were fabricated by three processes: micro end milling, EDM-milling and laser ablation.

For the fabrication of cavities by micro milling an end milling cutter made of hard metal with a diameter of $500 \mu \mathrm{m}$ was adopted. The material was removed in lines with an overlap of about $20 \%$ of the tool diameter.

During EDM-milling, the material was removed in a manner similar to micro milling in lines by a rod-shaped electrode (diameter: $600 \mu \mathrm{m}$ ). Between the tool electrode and the workpiece a non-conducting organic liquid was injected as a dielectric medium to facilitate the interaction between electrode and workpiece. For laser ablation, a Nd:YAG-laser with a power of $5 \mathrm{~mW}$ (repetition rate: $1 \mathrm{kHz}$, pulse energy: $5 \mu \mathrm{J}$ ) and a pulse duration of 15 ps was used. In this case the pulse and path distance was $2 \mu \mathrm{m}$. More details about the processing by micro milling, EDM-milling or laser ablation can be found in [11].

For surface finishing a blasting machine of the type IEPCO Peenmatic 770 equipped with an additional peening device Micropeen 200 with a nozzle diameter of $1.2 \mathrm{~mm}$ was built up and 
included in a 5 axis $\mathrm{CNC}$-device to provide an automated peening of micro cavities. CANBUS-controlled NC-axes with DC-servo motors of the type "Isel" were used. The x-, y- and z-axes in cartesian coordinates were embedded above the working chamber. A rotary disc (located at the bottom of the working chamber) and the jet nozzle can be rotated by $360^{\circ}$. The blasting agent consists of a mixture of $\mathrm{Al}_{2} \mathrm{O}_{3}, \mathrm{SiC}$ and glass beads with diameter between 10 and $20 \mu \mathrm{m}$.

The residual stress states in the samples were determined for the parallel and transverse directions with respect to the axes along which the mechanical surface treatments were performed. These two directions defined by the azimuthal angles $\varphi=0^{\circ}$ and $90^{\circ}$ on the instrumental coordinate system, refer to the two principal in-plane residual stresses $\sigma_{11}$ and $\sigma_{22}$. The $\sin ^{2} \psi$ method [12] was used to evaluate the residual stresses from the measured Xray diffraction strain data.

X-ray diffraction experiments were performed in reflection mode at the G3 beamline using a 4-circle diffractometer equipped with a scintillation counter behind a Soller collimator [13]. A monochromatic beam with wavelength set at $\lambda=0.1772 \mathrm{~nm}\left(\mathrm{E}_{\mathrm{ph}}=7 \mathrm{keV}\right)$ was collimated using an aperture size of $1.5 \times 1.5 \mathrm{~mm}$ which determined the apparent beam size on the sample surface. The $\alpha$-Fe $\{211\}$ Bragg peak profiles were recorded in the range $97^{\circ} \leq 2 \theta \leq$ $102^{\circ}$ at 21 different tilt angles in the range of $-85^{\circ} \leq \psi \leq 85^{\circ}$. The diffraction strain data were treated by first fitting a Pearson VII function to the Bragg peaks. The principal stresses $\sigma_{11}$ and $\sigma_{22}$ were computed using an evaluation method described in [14] suited for deducing the residual stress depth profile from non-linear curves in the $\sin ^{2} \psi$ plots. This method allows for the evaluation of the stress profiles in z-space, i.e. the true distance from the sample surface to depth in the material. Due to grain anisotropy, X-ray elastic constants were used for the evaluation (calculated in [12]). 
Additional X-ray diffraction measurements with a lower depth resolution were conducted using conventional X-rays generated from a sealed tube. A D500 Siemens diffractometer was used to scan the $\alpha-\mathrm{Fe}\{211\}$ Bragg peak at a characteristic spectrum of $\mathrm{Cr}-\mathrm{K} \alpha$ radiation $(\lambda=$ $\left.0.22897 \mathrm{~nm} ; \mathrm{E}_{\mathrm{ph}}=5.41 \mathrm{keV}\right)$. A range of $146^{\circ} \leq 2 \theta \leq 166^{\circ}$ at $\Delta 2 \theta=0.2^{\circ}$ at $5 \mathrm{sec} / \mathrm{step}$ were covered during the measurements. Thirteen inclination angles $\psi$ ranging from $-60^{\circ} \leq \psi \leq 60^{\circ}$ varied at intervals of $\Delta \psi=10^{\circ}$ were employed for the $\sin ^{2} \psi$-method.

\section{Results and Discussion}

Fig. 1 - 3 show scanning electron microscope (SEM) images obtained from typical machined surfaces after the different manufacturing processes. Feed marks caused by the tool movement can be observed on the micro milled surface (Fig. 1).

Fig. 1: SEM image of a micro milled surface

Fig. 2 shows a surface of a cavity manufactured by EDM. The surface texture after EDM is characterized by the typical discharge craters. This thermally influenced zone in EDM generally consists of several layers, as described in [15]. At the top a molten and resolidified layer is observed, also called the "white layer" or "recast layer". In this white layer, microcracks are often present due to the rapid solidification and shrinkage of the molten material. These circumstances decrease the quality of the micro mould and could induce defects in the demoulded micro parts.

\section{Fig. 2: SEM image of a surface manufactured by EDM-milling}

An example of a surface after laser-machining is shown in Fig. 3. For metals, the presence of melt during the laser processing always requires a balance between an efficient material removal in molten form and a reduction of quality due to the presence of a recast layer. Reducing the laser pulse duration can decrease the amount of produced melt and thus increase precision. The undesirable melt or recast formation is unavoidable as shown in Fig. 3. 
As mentioned in the introduction a micro peening process was applied to remove the undesired features at the topography of the sample surfaces. The image of a micro peened EDM-milled surface of a cavity is presented in Fig. 4. Feed marks or discharge craters due to the production process vanish, molten material is removed and a homogeneous surface topography is created.

Fig. 4: SEM image of a surface manufactured by EDM-milling after micro peening

The residual stress depth profiles measured using synchrotron X-rays are shown in Fig. 5 - 7. Fig. 5, which provides the residual stress profiles for the end milling process, indicates compressive stresses in the whole depth range covered by the measurements. The values of $\sigma_{11}$ and $\sigma_{22}$ at the surface, about $-300 \mathrm{MPa}$ and $-600 \mathrm{MPa}$, respectively, are quite different whereas in a depth of $4.5 \mu \mathrm{m}$ almost equal values in the range of about $-700 \mathrm{MPa}$ are observed. The reasons for the absence of rotational symmetry at the surface are due to the movement of the rotating miller in straight lines along the surface. This leads to changing orientation of the miller to the specimen axes and different undeformed chip thickness across the milling path. Thus the plastic deformation imparted to the surface layer and the conduction of the heat generated by machining is continuously changing from the left to the right side of the groove which leads to changes in the residual stresses, too. A detailed study on this issue can be found in [16].

Fig. 6 shows the residual stress depth profiles after EDM-milling. Similar to micro milling, a non-equiaxed biaxial stress state up to a depth of about $4 \mu \mathrm{m}$ can be seen. The value of $\sigma_{11}$ is constant at about $300 \mathrm{MPa}, \sigma_{22}$ transits from compressive stresses to tensile stresses at $\mathrm{z} \sim 2.5$ $\mu \mathrm{m}$ and than attains a value of about $300 \mathrm{MPa}$, creating an equi-biaxial stress state in the sample at $\mathrm{z} \sim 4.5 \mu \mathrm{m}$. The non-equiaxed biaxial stress state after EDM-milling in this sample can be accounted for using similar arguments as in the case of micro milling, since the tool electrode also moves in straight lines over the workpiece area. These tensile stresses up to 300 
MPa, shown in Fig. 6, verify the thermally influenced zone after the machining process. The shrinkage created during cooling of the hot rim zone after EDM-milling is constrained by the cold underlying bulk material. This induces tensile stresses in the near surface region. In this heat affected zone micro-cracks can occur which is detrimental for the intended micro powder injection moulding. A smaller rim zone is often associated with reduced residual tensile stresses, thus also reducing the negative influence on service life of a manufactured part or tool. A detailed study of the properties of surface layers after EDM-milling can be found in $[15]$.

The depth profiles after laser ablation, Fig. 7, show that compressive residual stresses lie between -100 and -300 MPa. The movement of the laser focus over the surface in lines induces an effect which is similar to that of micro milling or EDM-milling. A non-equiaxed biaxial stress state is observed at the surface of the cavity and then at a depth of $4.5 \mu \mathrm{m} \sigma_{11}$ and $\sigma_{22}$ become equal. The stress gradient in this case is lower than for the other machining processes. The final surface properties after the interaction of short laser pulses with metal targets depend on material properties as well as on laser parameters such as pulse duration or energy. To understand the formation of residual stresses after processing with lasers the evolution of the absorbed energy which involves thermalisation within the electron subsystem, energy transfer to the lattice and energy losses due to the electron heat transport into the target, has to be considered. Studies, reported in [17], provide theoretical models of laser ablation which are confirmed by experiments describing the influence of different pulse durations on the surface quality. These low compressive stresses shown in Fig. 7 indicate that the energy deposited into the solid and the heat-affected zone is minimized.

Fig. 5: Residual stress state of a micro milled surface before (dotted line: $\varphi=0^{\circ}$, dotted dashed line: $\varphi=$ $90^{\circ}$ ) and after micro peening (solid line: $\varphi=0^{\circ}$, dashed line: $\varphi=90^{\circ}$ )

Fig. 6: Residual stress state of an EDM-milled surface before (dotted line: $\varphi=0^{\circ}$, dotted dashed line: $\varphi=$ $90^{\circ}$ ) and after micro peening (solid line: $\varphi=0^{\circ}$, dashed line: $\varphi=90^{\circ}$ )

Fig. 7: Residual stress state of a surface machined by laser ablation before (dotted line: $\varphi=0^{\circ}$, dotted dashed line: $\varphi=90^{\circ}$ ) and after micro peening (solid line: $\varphi=0^{\circ}$, dashed line: $\varphi=90^{\circ}$ ) 
Fig. $5-7$ also indicate that after micro peening high compressive residual stress states in the range of -800 to $-1000 \mathrm{MPa}$ are induced in the samples. Such a stress state is beneficial to $\mu \mathrm{PIM}$ applications. The residual stress states after micro peening in the samples presented in the Fig. 5 - 7 are equi-biaxial in nature as is evidenced by the similar courses for $\varphi=0^{\circ}$ and $90^{\circ}$. Similar profiles of the residual stress states after micro peening (Fig. $5-7$ ) indicate that they are not influenced by the previous mechanical processes. In all three cases a low negative gradient is apparent.

To overcome the limitations of the X-ray penetration depth which is restricted to approximately $8 \mu \mathrm{m}$ layer removal method was carried out. In order to check the influence of micro peening on the residual stress at depth below $5 \mu \mathrm{m}$ in the samples, a stress free state was prepared. Measurements with conventional X-ray sources as described in the experimental part validate the stress free surface before micro peening (Fig. 8). It can be seen in Fig. 8 that after micro peening an equi-biaxial compressive residual stress of about -720 MPa was induced in the sample surface. This value is somewhat different from measurements conducted using synchrotron sources because of different instrumental resolutions and penetration depth within the sample volume. To measure the residual stress value in a certain depth, a surface layer of about $10 \mu \mathrm{m}$ was sequentially removed by electrochemical polishing. A residual stress value of about $-300 \mathrm{MPa}$ was observed after the first layer removal of $10 \mu \mathrm{m}$ and in a depth of $20 \mu \mathrm{m}$ the residual stress appears to vanish to zero. No corrections were made of the measured values. This result offers a clear indication that micro peening affects only the first 10 to $15 \mu \mathrm{m}$ surface layers of a quenched and tempered steel type.

Fig. 8: Residual stress depth profile after micro peening of a stress free state

\section{Conclusions}

High-resolution X-ray diffraction studies on a Toolox 44 steel type showed that the residual stress state in the surface after different fabrication processes have different depth profiles in 
the two in-plane directions, defined by $\varphi=0^{\circ}$ and $90^{\circ}$. The evidence of the thermal character of EDM-milling or laser ablation can be supported by tensile or very low compressive stresses in the near surface regions. Micro peening results in rotationally symmetric high compressive residual stresses which are confined to the near surface layers with thicknesses of about $10-$ $15 \mu \mathrm{m}$. Residual stress states corresponding to the initial fabrication processes micro milling, EDM-milling and laser ablation vanish within this surface layer. Further investigations are planned to reveal the influence of surface topography, surface roughness and residual stress state on the tribological behaviour of micro moulds.

[1] V. Piotter, T. Benzler, T. Gietzelt, R. Ruprecht, J. Haußelt, Advanced Engineering Materials, 2000, 2, 10, 639.

[2] J. Schneider, H. Iwanek, K.-H. Zum Gahr, Wear, 2005, 259, 1290.

[3] J. Schmidt, V. Hüntrup, H. Tritschler, wt werkstattstechnik online, 1999, 89, 11/12, 495.

[4] J. Fleischer, J. Schmidt, S. Haupt, G. Halvadjiysky, A Quadroni, wt werkstattstechnik online, 2006, 96, 11/12, 844 .

[5] J. Fleischer, J. Schmidt, S. Haupt, Microsystem Technologies, 2006, 12, 697.

[6] C. Horsch, V. Schulze, D. Löhe, in Advanced micro and nanosystems, (Eds.: D. Löhe, J. Haußelt), Vol. III: Micro-engineering in metals and ceramics, Wiley-VCH, Weinheim, 2005, 221.

[7] G. Cusanelli, A. Hessler-Wyser, F. Bobard, R. Demellayer, R. Perez, R. Flükiger, J. of Materials Processing Techn., 2004, 149, 289.

[8] R. Le Harzic, D. Breitling, M. Weikert, S. Sommer, C. Föhl, F. Dausinger, S. Valette, C. Donnet, E. Audouard, Appl. Phys. A, 2005, 80, 1589.

[9] T. Beck, D. Löhe in Kolloquium Mikroproduktion (Eds.: U. Dilthey, T. Dorfmüller), 2005, 23. 
[10] C. Horsch, V. Schulze, D. Löhe, Microsystem Technologies, 2006, 12, 7, 691.

[11] J. Fleischer, J. Schmidt, S. Haupt, G. Halvadjisky, J. Kotschenreuther, wt werkstattstechnik online, 2005, 95, 11/12, 887.

[12] E. Macherauch, P. Müller, Z. f. Angew. Phys., 1961, 13, 305.

[13] T. Wroblewski, O. Clauß, H.-A. Crostack, A. Ertel, F. Fandrich, Ch. Genzel, K. Hradil, W. Ternes, E. Woldt, Nuclear Instruments \& Methods in Physics Research A, 1999, 428,570 .

[14] T. Erbacher, in Werkstoffwissenschaft und Werkstofftechnik, PhD Thesis, Shaker Verlag, 2006, 2006, 32.

[15] P. Bleys, J.-P. Kruth, B. Lauwers, B. Schacht, V. Balasubramanian, L. Froyen, J. Van Humbeck, Advanced Engineering Materials, 2006, 8, 1-2, 15

[16] K. Jacobus, S. G. Kapoor, R. E. DeVor, G. E. Dullerud, Transactions of the ASME, 2001, 123, 748

[17] B. N. Chichkov, C. Momma, S. Nolte, F. von Alvensleben, A. Tünnermann, Applied Physics A, 1996, 63, 109

[*] Dipl.-Phys. Andreas Kienzler Institut für Werkstoffkunde I Universität Karlsruhe (TH)

Kaiserstrasse 12

D-76131 Karlsruhe Germany

Tel.: $++49 / 721 / 608-7441$

Fax: $++49 / 721 / 608-8044$

E-mail: andreas.kienzler@,iwk1.uni-karlsruhe.de

[**] The financial support of the investigations performed, carried out in the collaborative research centre 499 "Development, production and quality assurance of moulded micro-components made out of metallic and ceramic materials" by the DFG is gratefully acknowledged.

The authors would like to thank Dr. André Rothkirch for his kind support at the beamline G3 at Hasylab/Desy.

Fig. 1 


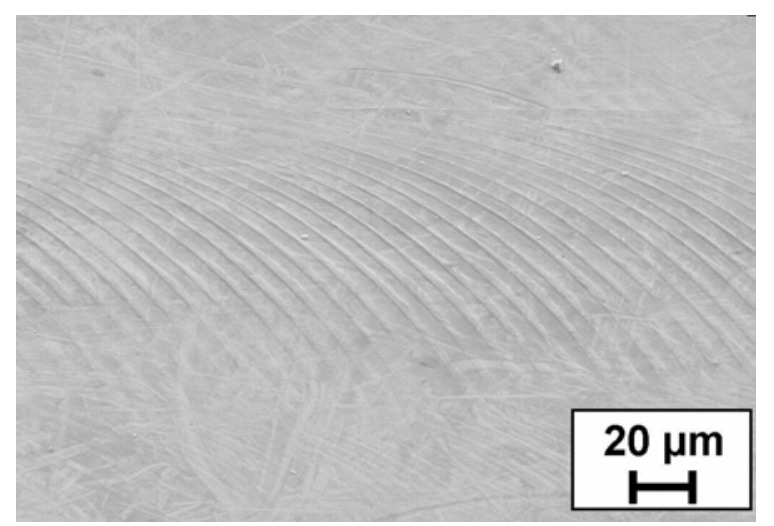

Fig. 2

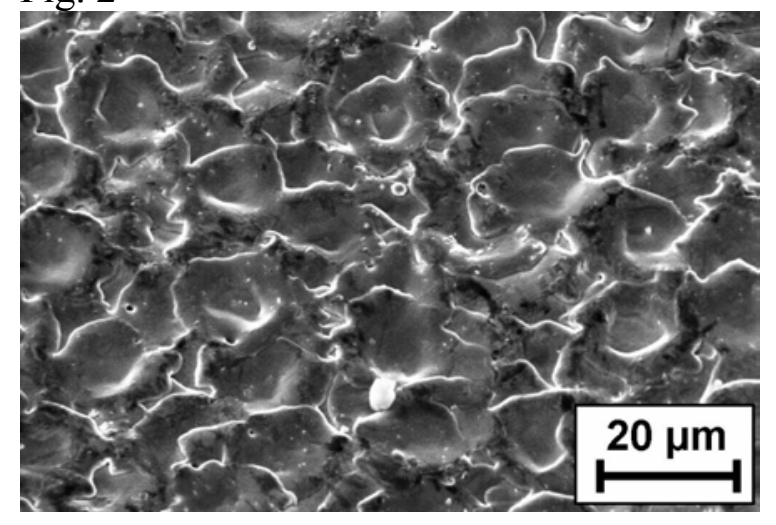

Fig. 3

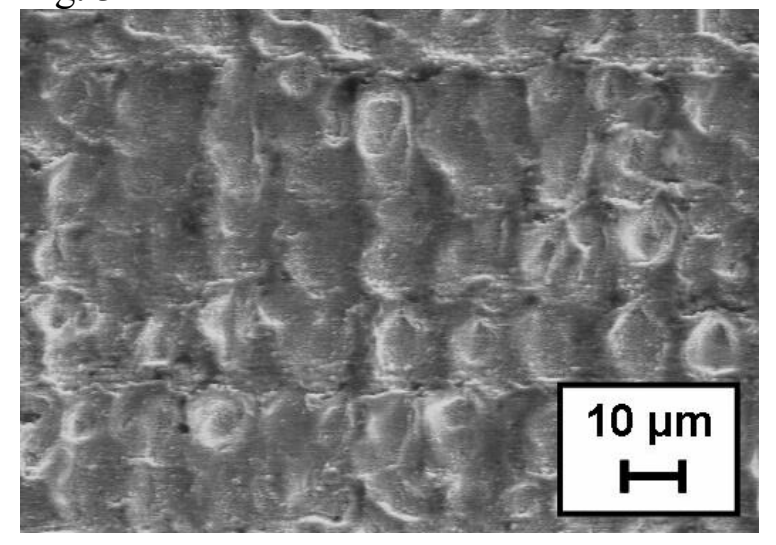

Fig. 4

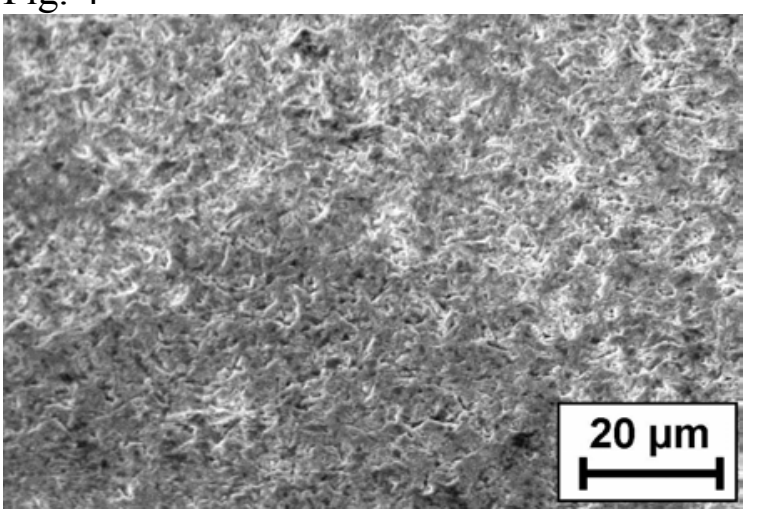


Fig. 5

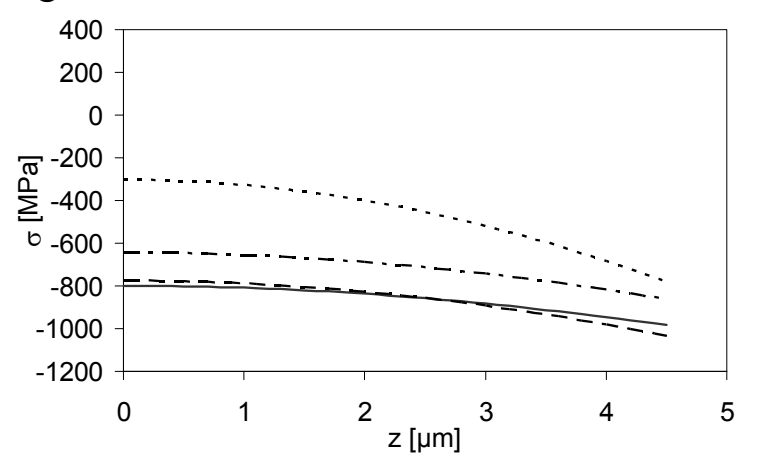

Fig. 6

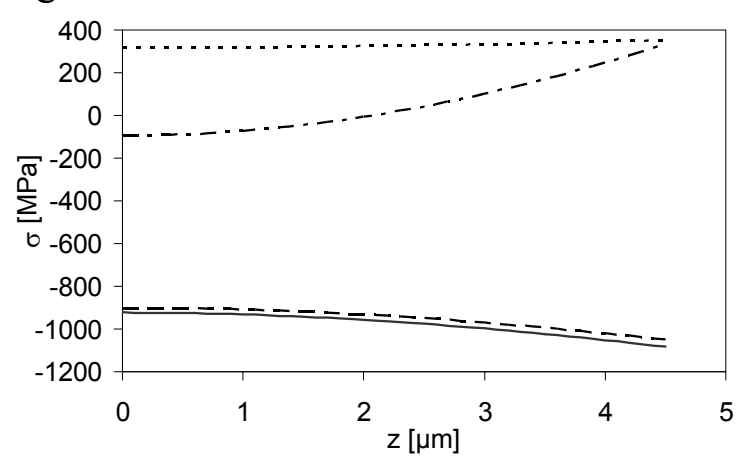

Fig. 7

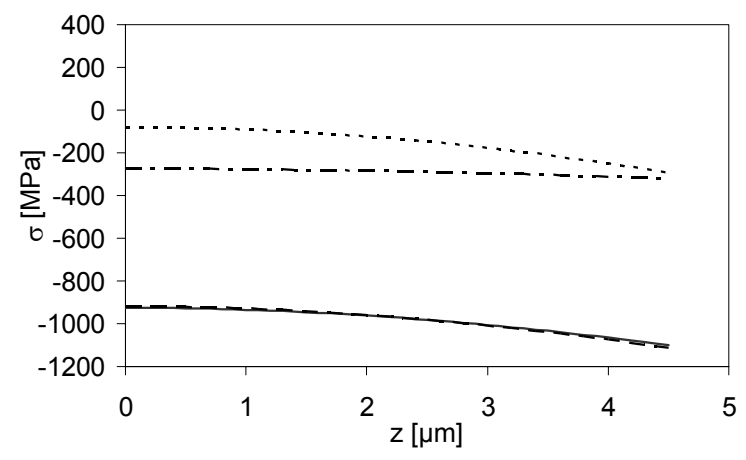

Fig. 8

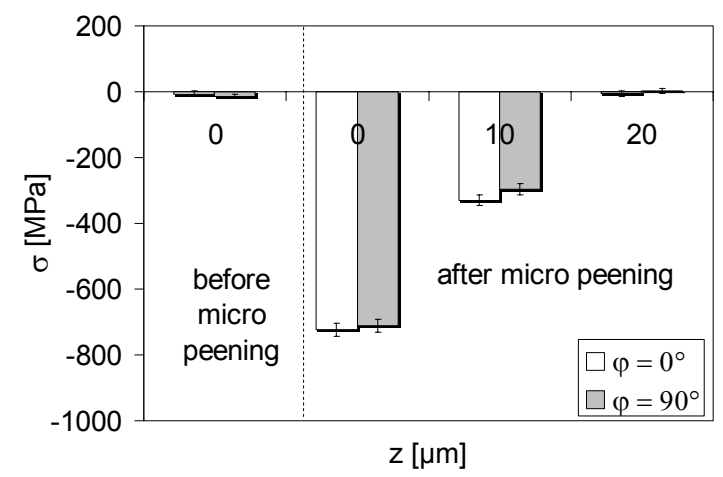

